\section{DESENVOLVIMENTO DE CAPACIDADES LOCAIS PARA A INOVAÇÃO: Estudo de caso sobre uma subsidiária brasileira de corporação multinacional}

\author{
LOCAL DEVELOPMENT CAPABILITIES \\ FOR INNOVATION: CASE STUDY OF \\ BRAZILIAN SUBSIDIARY FROM A \\ MULTINATIONAL CORPORATION
}

Seimor Walchhütter - Centro Universitário da $\mathrm{FEI}^{22}$

Sandra Valéria Walchhütter Universidade de Taubaté (UNITAU)

Marcello Romani Dias - Centro Univeritário da $\mathrm{FEI}^{23}$

Aline dos Santos Barbosa - Centro Universitário da $\mathrm{FEI}^{24}$ Resumo: Este trabalho pretende investigar qualitativamente a trajetória de

\footnotetext{
${ }^{22}$ Doutorando e Mestre em Administração pelo Centro Universitário da Fei. Especialização em Administração Industrial pela USP _ Fundação Vanzolini. Pós-graduação Lato-Sensu em Química pela Faculdade de Eng. Industrial Oswaldo Cruz e Graduação em Química Bacharelado pela Universidade de São Bernardo do Campo. Professor universitário nos cursos de graduação e pós-graduação do Centro Universitário SENAC, Universidade Ibirapuera e FEI Campus-SP. Filiação Institucional_Centro Universitário da FEI-SP, Rua Tamandaré, 688, São Paulo - SP, Brasil. CEP 01525-000. E-mail: wseimor@uol.com.br tel. (011) 99310-8175 e (011) 4156-5322

2323 Mestrando em Administração pelo Centro Universitário da FEI. Professor no curso de graduação na Universidade Ibirapuera. Filiação Institucional_Centro Universitário da FEI, Rua Tamandaré, 688, São Paulo - SP, Brasil. CEP 01525-000. Telefone: (11) 7788-7543. E-mail: mromdias@hotmail.com

24 Mestranda em Administração pelo Centro Universitário da FEI. Consultora de Marketing na Companhia Ultragaz S/A. Filiação Institucional_Endereço: Avenida Barão de Monte Mor, 330 apto. 41 - São Paulo - SP, Brasil. CEP 05687-010. Telefone: (11) 96623-8494.E-mail: aline.publicidadeepropaganda@gmail.com
}

desenvolvimento das capacidades locais para a inovação da Cognis Brasil, subsidiária da matriz alemã pioneira em estabelecer diferentes trajetórias de inovação tecnológica de acordo com cada uma de suas unidades estratégicas de negócios em diferentes países. O trabalho desenvolveu sua análise teórico-analítica com base na perspectiva teórica da Gestão Estratégica da Inovação pretendendo caracterizar os esforços de adensamento das atividades de Pesquisa e Desenvolvimento (P\&D) e do processo de desenvolvimento de produtos. Foi proposto um estudo de caso único, descritivo e exploratório, o qual utilizou survey presencial. Os resultados encontrados indicam que a subsidiária confere esforços significativos e rotinas independentes para o desenvolvimento de capacidades orientadas para a inovação conforme identificado por Dodgson (2008).

Palavras-Chave: Capacidades Dinâmicas; Inovação Tecnológica; Agroindústria

\begin{abstract}
This paper aims to investigate qualitatively the trajectory of development of local capacity for innovation from Cognis Brazil, a subsidiary of pioneer in establishing different paths of technological innovation according to each of its strategic business units in different countries. The work developed his theoretical and analytical analysis based on the theoretical perspective of the Strategic Management of Innovation intending to characterize the densification efforts of Research and Development $(R \& D)$ and product development process activities. A single, descriptive and exploratory case study, which used face survey, was proposed. The results indicate the subsidiary confers significant efforts and independent routines for capacity development oriented to innovation as identified by Dodgson (2008).
\end{abstract}

Keywords: Dynamic Capabilities; Technological innovation; Agribusines 


\section{Introdução}

Este trabalho teve sua origem a partir de uma indagação de pesquisa categorizada a partir dos estudos de Dodgson (2008): Por que a inovação continua sendo um tema de estudo tão importante para a compreensão da trajetória de crescimento e competitividade das empresas? Uma possível resposta para esta pergunta é a seguinte: Porque em um ambiente econômico de acirrada competição globalizada e perfil de demanda volátil e customizada, somente por meio da inovação é possível que as empresas obtenham novas fontes de crescimento, rentabilidade e sobrevivência a curto, médio e longo prazos (Schumpeter, 1961; Dodgson, 2008). Esta indagação foi utilizada como pano de fundo para a premissa da pesquisa de que as indústrias regionais de corporações multinacionais estão cada vez mais deixando de ser apenas canais de acesso à outros países, mas acrescentando valores às matrizes por meio de suas atividades tecnológicas locais (OLIVEIRA Jr. M. M., et al., 2009). Este estudo filia-se ao conjunto de estudos que apontam o adensamento das atividades de inovação em subsidiárias multinacionais e sua relevância estratégica para a corporação, reconhecendo necessidades do mercado local e reagindo estratégica e tecnologicamente na direção destas necessidades. É por meio do desenvolvimento de capacidades e implantação de estratégias de inovação bem sucedidas que as empresas podem deter vantagem competitiva, e por isso é crítico para uma empresa acumular capacidades para gerenciamento do setor de pesquisa e desenvolvimento (P\&D), promovendo novas oportunidades para desenvolvimentos distintos e novos produtos e mercados. Nesse contexto, o objetivo deste trabalho consiste em investigar a trajetória de desenvolvimento das capacidades locais para a inovação da Cognis Brasil. Estratégias de adensamento tecnológico impulsionadas pela franca expansão deste mercado e perspectivas futuras muito promissoras num país de economia emergente, cenário que reflete o processo de organização da inovação à luz das tensões da gestão global da P\&D na matriz e os limites de autonomia das decisões de centralização e descentralização das atividades de inovação para a subsidiária brasileira.

A metodologia utilizada neste trabalho foi uma investigação exploratória por meio de estudo de caso único, e focada numa empresa que busca diferencial competitivo por inovação. Elaborou-se um instrumento de pesquisa baseado nos estudos dos modelos conceituais desenvolvidos por Dodgson (2008). Estes modelos buscaram compreender as atividades de organização e desenvolvimento da inovação a partir do 


\section{DIVERSQ!}

seu alinhamento com a visão estratégica das empresas. Embora a definição entre recursos, competências e capacidades sejam definidas da mesma maneira dentre várias literaturas, conforme descrito na obra de Barney, (1991); Wernerfelt (1984), este trabalho tratará dos termos "recursos" e "competências" como capacidades de forma geral. Neste sentido, são os recursos da empresa, utilizados de forma concomitante como competências e capacidades, as quais criam e proporcionam de forma lucrativa, potencial de diferenciação acumulado e disponível no mercado, (FLEURY; FLEURY, 2001). Esta visão foi analisada no decorrer do trabalho juntamente com a Teoria das Capacidades Dinâmicas da Firma (TEECE, PISANO E SCHUEN, 1997), uma vez que demonstra alta capacidade de gerenciamento no reposicionamento das capacidades de acordo com a velocidade da mudança das exigências do mercado.

\section{Recursos, Competências e Capacidades Dinâmicas}

O acúmulo de competências e conhecimentos tecnológicos para desenvolvimento de produtos torna-se cada vez mais essencial para a competitividade. Por meio da evolução da Teoria dos Recursos da Firma para um conceito que envolve as "Capacidades Dinâmicas" que, segundo Teece et. al. (1997), apresenta-se como uma resposta à questão da competitividade em ambientes de alta complexidade e mudança, nos quais a constatação de que o acúmulo de ativos tecnológicos (recursos) não é suficiente para garantir estratégias competitivas, mas, advém da importância atribuída à capacidade que a firma possui de coordenar competências internas e externas de forma a adaptar-se a um ambiente em rápida transformação. $\mathrm{O}$ conceito de "capacidade" enfatiza a necessidade de adaptar, integrar e reconfigurar apropriadamente as competências organizacionais internas e externas e os recursos na direção das mudanças do ambiente, sendo que a perspectiva "dinâmica" refere-se à flexibilidade e agilidade da empresa em posicionar-se estrategicamente frente a este fenômeno. $\mathrm{O}$ amadurecimento das Capacidades Dinâmicas da Firma provém de experiências pré-estabelecidas de processos (mecanismos de aprendizagem), e alicerça-se sobre a codificação da experiência adquirida.

Ao compreender as competências e Capacidades Dinâmicas como fontes de estratégia para as empresas, é possível questionar-se sobre como chegar às capacitações para a inovação e promoção de vantagem competitiva. Para tanto, Teece et. al., (1997), identificam três paradigmas - não com o intuito de desconstruir os argumentos, mas sim, de 
ampliá-los. Primeiro, a partir de uma visão Porteriana (PORTER, 1980), os autores destacam como as empresas podem desenvolver posições de vantagem contra as forças da concorrência; em segundo lugar, transitando para uma abordagem da teoria dos jogos, destacando e exemplificando casos empíricos sob a perspectiva concorrencial dentre as empresas, e por último, construir uma vantagem competitiva norteando os recursos das empresas. Sob esta perspectiva, torna-se fundamental destacar que quanto mais tácito for o conhecimento produtivo da firma, mais difícil será para seus competidores replicá-lo. Entretanto, segundo Fleury e Fleury (2001) estas habilidades devem ser aplicadas na prática e comunicadas para serem consideradas capacidades que gerem valor, tanto para a organização como para a firma.

Esta abordagem, de forma generalizada, concentrou o conhecimento humano como recurso para as Capacidades Dinâmicas da firma. Nesta direção, muitas empresas tendem a codificar seus conhecimentos tácitos de forma a se proteger. A funcionalidade das Capacidades Dinâmicas pode ser facilmente replicada, contudo, construir novas configurações de trabalho, processos ou agilidade na tomada de decisões, pode perfazer vantagem competitiva, mesmo que temporária, diferentemente da Visão Baseada em Recursos (RBV), segundo a qual as vantagens competitivas são consideradas longínquas Barney (1991). De fato, os atributos para o conceito de Capacidades Dinâmicas da firma não são vagos e/ou tautológicos como na RBV, mas efetivamente claros e idiossincráticos em seus caminhos em relação aos mecanismos de aprendizagem. Dodgson (2008) descreve a articulação de recursos de maneira estratégica, a qual, por meio das capacidades inovadoras, permite à empresa explorar oportunidades e neutralizar ameaças decorrentes do ambiente externo.

\section{Alinhamento entre Capacidades e Inovação da Empresa}

A evolução tecnológica dos ambientes organizacionais e a integração dos mercados mundiais fazem com que a capacidade de mudança organizacional seja essencial à sobrevivência das firmas, estabelecendo interface com a estratégia de negócios Mintzberg (1998), a qual pode ser considerada como falta de aderência da estratégia ao mundo real. Embora um dos fatores que sustentem a vantagem competitiva seja a inovação, ela por si só não basta, não sendo garantia absoluta de sucesso. O modo pelo qual o processo de inovação é conduzido, também é importante. Segundo alguns autores contemporâneos (TIDD, BESSANT E PAVITT, 2008) e (DODGSON, 2008), a 


\section{DIVERS@!}

ideia de desenvolvimento da inovação é a de estruturar, sob a luz de uma perspectiva estratégica, rotinas e sistematização que permitam a que a inovação seja formada e organizada de forma coerente dentro da estrutura organizacional. Dodgson (2008), demonstra que uma ferramenta pode ser utilizada mais de uma vez em estágios diferentes. A lógica consiste em orientar o tomador de decisão com acurácia a partir da estratégia de negócios e recursos da empresa.

Figura 1: Ferramentas e Técnicas de Suporte às Capacidades Inovadoras
A velocidade pela qual uma empresa lança novos produtos é diretamente proporcional à sua competitividade (COOPER, 1990:1996), e para isto, é determinante a busca pela melhoria continua dos processos produtivos e de inovação. O autor sugere o emprego de um mapa conceitual (Stage-Gate) dos estágios de lançamento de novos produtos para determinar a eficiência e eficácia do projeto. Este modelo permite análise sobre os pontos de sucesso, melhoria e avanço ou não do projeto.
Capacidade Inovadora

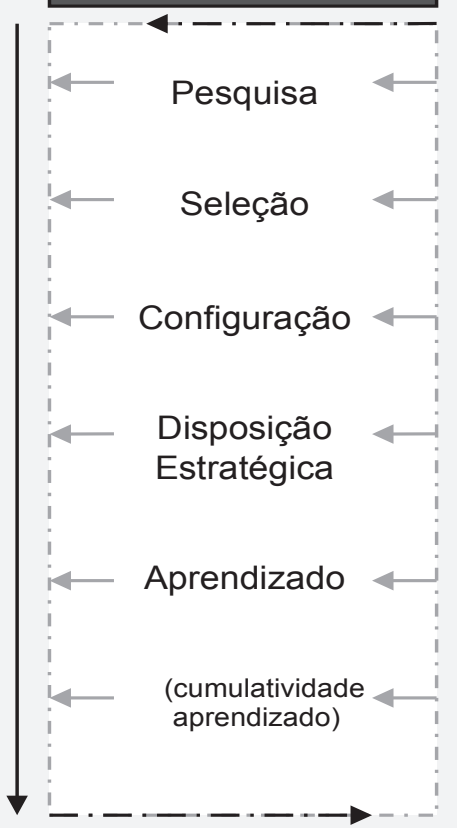

O que fazer?

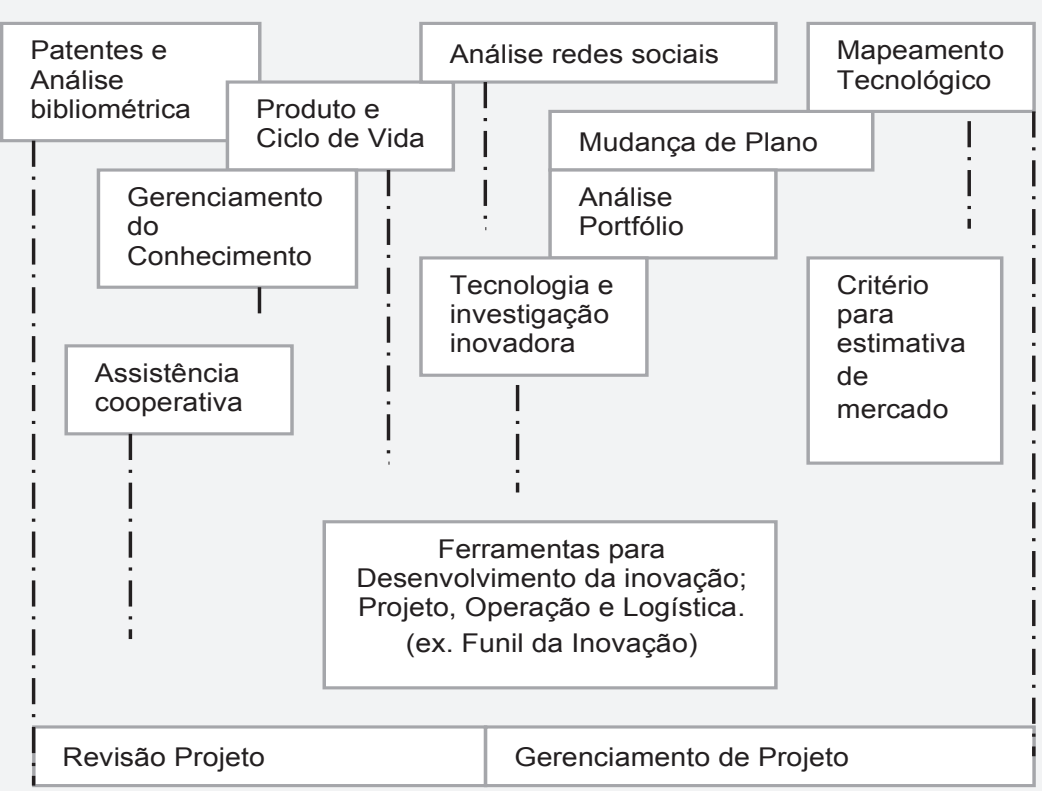

Fonte: Dodgson (2008, p.107). 


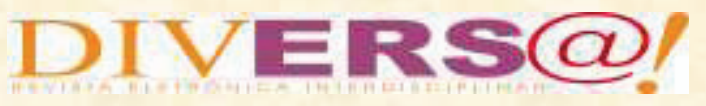

Figura 2: Ferramentas e Técnicas de Suporte às Capacidades Inovadoras

\section{Modelo Stage-Gate ${ }^{\mathrm{TM}}$ - da Geração da Idéia ao Lançamento efetivo do Produto}

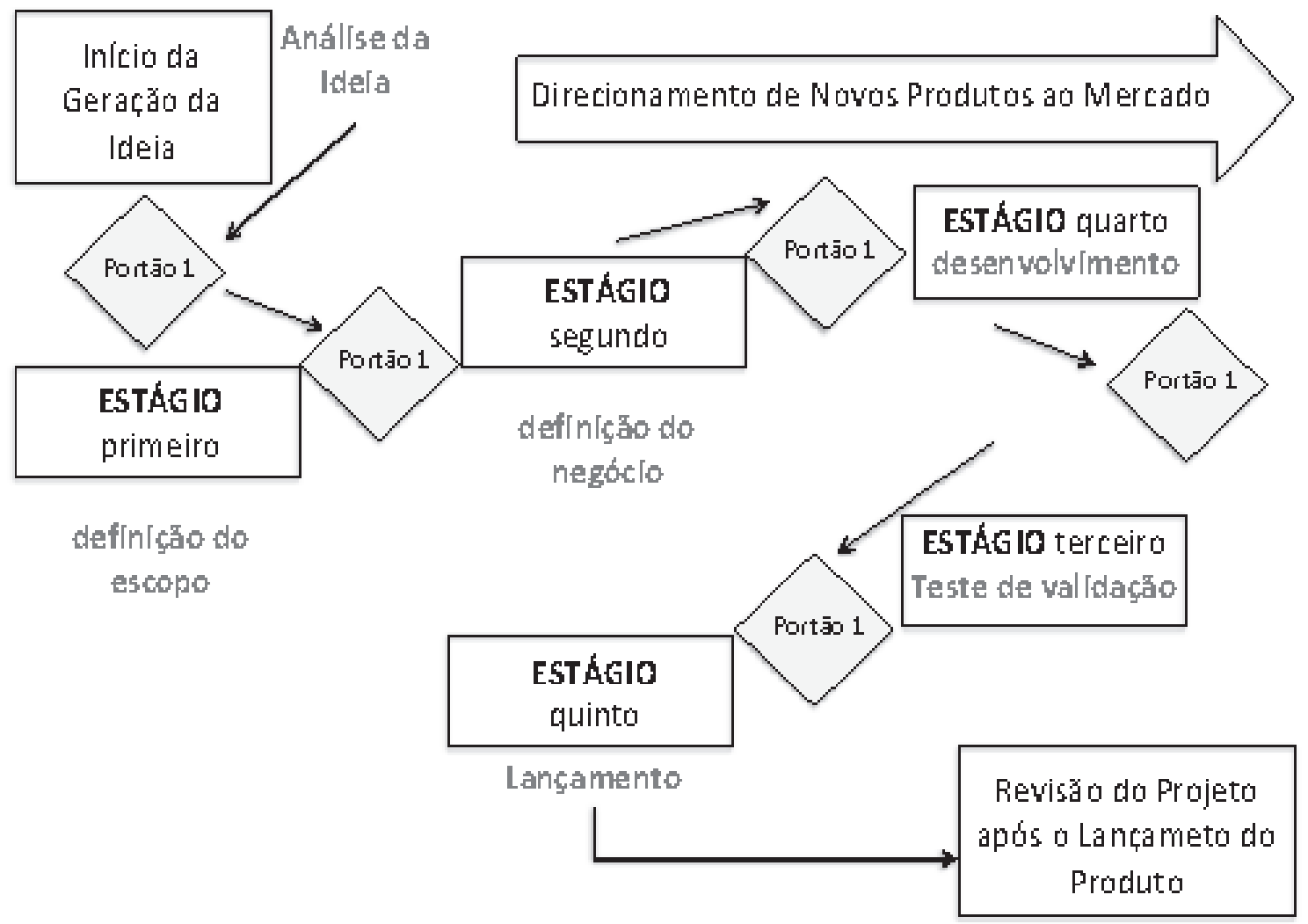

Fonte: Cooper (1990: 1996).

Portanto, a estratégia de desenvolvimento da inovação consiste em estruturar rotinas e ferramentas as quais permitam que a inovação seja uma operação articulada, organizada e sistematizada sob uma perspectiva estratégica (Vilha; Quadros, 2008) e (Quadros, 2008).
4. Métricas de Inovação na Subsidiária Brasileira

A Cognis Brasil, entende e determina como principais indicadores de suas

atividades inovadoras os seguintes aspectos: (i) o número de patentes depositadas; (ii) o número de projetos em seu "pipeline" tecnológico; (iii) volume de vendas em toneladas de produtos desenvolvidos e lançados no mercado nos últimos cinco anos; (iv) faturamento líquido em milhões de reais relativo ao 


\section{DIVERS@!}

lançamento de produtos novos em referência ao total do faturamento da empresa. Os indicadores de sustentabilidade e responsabilidade socioambiental da empresa são contemplados no item 6.5 .

A partir da Tabela a seguir é possível notar que o faturamento projetado a partir das atividades tecnológicas consideravelmente que o das atividades de Número total de funcionários da vendas ou alteração de produtos, geralmente motivadas pela adequação de competitividade em custos. Isto significa que o retorno do investimento sobre atividades tecnológicas alinhado ao processo de gestão estratégico da inovação torna-se mais interessante que inovações desenvolvidas a partir de estratégias de vendas ou produtos. Desta forma, conforme demonstra a tabela 1, há aumento dos investimentos em P\&D indicando que há tendência na mudança da estratégia da empresa na busca de aumentar a lucratividade através dos esforços em P\&D com a intenção de elaborar produtos de maior valor agregado sob percepção do cliente final ao mesmo tempo em que ocorre adequação de custos pela gestão de pessoas, fato evidenciado pelo aumento do número total de funcionários alocados na área de tecnologia com redução simultânea do número total de funcionários da empresa.

Tabela 1: Recursos Disponibilizados para Área de P\&D na Cognis Brasil 


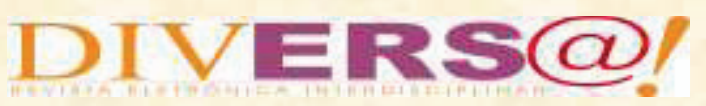

Tabela 2: Projeto "Pipeline” para Região Mercosul - visão 2009/2013 em MBRL

\begin{tabular}{l|l|l|l|l|c|c}
\hline & & & \multicolumn{3}{|c|}{$\begin{array}{c}\text { Categoria do } \\
\text { Projeto }\end{array}$} & \\
\hline SBU_FP & $\begin{array}{l}\text { Total de } \\
\text { Projetos }\end{array}$ & $\begin{array}{l}\text { Projetos } \\
\text { Ativos }\end{array}$ & $\begin{array}{l}\text { Novos } \\
\text { Negócios }\end{array}$ & $\begin{array}{l}\text { Retenção } \\
\text { de } \\
\text { Negócios }\end{array}$ & $\begin{array}{c}\text { Substituição } \\
\text { de } \\
\text { Negócios }\end{array}$ & $\begin{array}{c}\text { Projetos } \\
\text { Aguardando } \\
\text { Aprovação }\end{array}$ \\
\hline Agronegócio & 123,40 & 118,10 & 74,30 & 0,00 & 43,80 & 5,30 \\
\hline PCI & 21,78 & 7,08 & 3,29 & 1,92 & 1,88 & 14,70 \\
\hline Lubrificantes & 13,12 & 7,90 & 7,90 & 0,00 & 0,00 & 5,22 \\
\hline Total & $\mathbf{1 5 8 , 3}$ & $\mathbf{1 3 3 , 0 8}$ & $\mathbf{8 5 , 4 9}$ & $\mathbf{1 , 9 2}$ & $\mathbf{4 5 , 6 8}$ & $\mathbf{2 5 , 2 2}$ \\
\hline
\end{tabular}

Fonte: Dados primários Cognis Brasil Ltda, (2110).

Tabela 3 : Projetos "Pipeline" de Vendas por Produtos - visão 2009/2013 em MBRL

\begin{tabular}{l|c|c|c|c|c|c}
\hline & & \multicolumn{3}{|c|}{$\begin{array}{c}\text { Categoria } \\
\text { do Projeto }\end{array}$} \\
\hline $\begin{array}{c}\text { Unidade } \\
\begin{array}{c}\text { Estratégica } \\
\text { de Negócio_ } \\
\text { FP }\end{array}\end{array}$ & $\begin{array}{c}\text { Total de } \\
\text { Projetos }\end{array}$ & $\begin{array}{c}\text { Projetos } \\
\text { Ativos }\end{array}$ & $\begin{array}{c}\text { Novos } \\
\text { Negócios }\end{array}$ & $\begin{array}{c}\text { Retenção de } \\
\text { Negócios }\end{array}$ & $\begin{array}{c}\text { Substituição } \\
\text { de Negócios }\end{array}$ & $\begin{array}{c}\text { Projetos } \\
\text { Aguardando } \\
\text { Aprovação }\end{array}$ \\
\hline Agronegócio & 9,54 & 7,10 & 5,25 & 1,97 & 0,00 & 2,44 \\
\hline PCI & 8,62 & 3,86 & 3,86 & 0,00 & 0,00 & 4,76 \\
\hline Lubrificantes & 2,84 & 2,84 & 2,84 & 0,00 & 0,00 & 0,00 \\
\hline Total & $\mathbf{2 1 , 0 0}$ & $\mathbf{1 3 , 8 0}$ & $\mathbf{1 1 , 9 5}$ & $\mathbf{1 , 9 7}$ & $\mathbf{0 , 0 0}$ & $\mathbf{7 , 2 0}$ \\
\hline
\end{tabular}

Fonte: Dados primários Cognis Brasil Ltda, (2110). 


\section{Panorama Setorial}

Quadro 1: Trajetória Tecnológica da Indústria de Agroquímicos

\begin{tabular}{|c|c|c|}
\hline Período & Características do Período Histórico & Fator Tecnológico \\
\hline Meados dos anos 40 até anos 50 & $\begin{array}{c}\text { Poucos concorrentes. Baixa } \\
\text { legislação regulatória. Inexistência } \\
\text { de controle toxicológico. }\end{array}$ & $\begin{array}{l}\text { Fácil e rápido desenvolvimento e } \\
\text { aplicação de novos produtos, } \\
\text { geralmente sintéticos. }\end{array}$ \\
\hline Década de 60 e 70 & $\begin{array}{l}\text { Consolidação da indústria química e } \\
\text { alta importação de produtos } \\
\text { acabados. Concorrência e legislação } \\
\text { mais acirradas. Aumento do } \\
\text { consumo de herbicidas. }\end{array}$ & $\begin{array}{l}\text { Incorporação de insumos modernos. } \\
\text { Início de diferencial competitivo por } \\
\text { inovação tecnológica. Predomínio de } \\
\text { agroquímicos sintéticos. }\end{array}$ \\
\hline Década de 80 & $\begin{array}{l}\text { Crise do petróleo e encerramento de } \\
\text { subsídios (créditos rurais) agrícolas. } \\
\text { Entrada de produtos genéricos. }\end{array}$ & $\begin{array}{l}\text { Desenvolvimento de produtos cada } \\
\text { vez mais específicos para garantir } \\
\text { vantagem competitiva. Mistura de } \\
\text { mais de um "ativo" (pesticida) se } \\
\text { tornou estratégia comum para novos } \\
\text { desenvolvimentos. }\end{array}$ \\
\hline Década de 90 & $\begin{array}{l}\text { Acentuado processo de fusões e } \\
\text { aquisições. Sete empresas controlam } \\
\text { o mercado global de defensivos } \\
\text { agrícolas e preocupam-se com a } \\
\text { saúde humana e ambiental. }\end{array}$ & $\begin{array}{l}\text { Concentração de esforços em P\&D. } \\
\text { Pelo esgotamento de tecnologias } \\
\text { tradicionais, inicia-se um processo } \\
\text { pela busca de novas tecnologias. } \\
\text { Caracterização de produtos } \\
\text { específicos }\end{array}$ \\
\hline Anos 2000 & $\begin{array}{l}\text { Matrizes internacionais incentivam e } \\
\text { disponibilizam sua estratégia de } \\
\text { mercado e plataforma tecnológica às } \\
\text { subsidiárias. }\end{array}$ & $\begin{array}{l}\text { Inicia-se desenvolvimento de novos } \\
\text { produtos a partir da biotecnologia. }\end{array}$ \\
\hline
\end{tabular}

Fonte: Elaborado e adaptado pelo autor de: (MARTINELLI, 2005, p. 17-21)

A empresa Cognis Brasil Ltda, objeto desta pesquisa, detém três principais unidades estratégicas de negócios (SBU). Uma de suas forças competitivas está no fato de possuir tecnologia moderna no processo de fabricação de intermediários para defensivos agrícolas. Desta forma, o deslocamento das atividades tecnológicas no nível de P\&D ao centro de competências tecnológicas da matriz tornou-se realidade, um fato interessante foi identificado: a subsidiária pôde investir mais tempo em pesquisa de aplicação 
atendendo melhor seu cliente, regional. A matriz, por sua vez, passa a preocupar-se de forma eficaz no desenvolvimento de novas tecnologias (desenvolvimento de novas moléculas) focadas nas tendências de mercado, para posteriormente transferir seu conhecimento às subsidiárias, as quais passam a desenvolver a aplicação do produto no que se refere à solução de problemas específicos. Neste contexto, de acordo com Oliveira, Jr. (2009), o modelo pelo qual a subsidiária é reconhecido passa a ser de mandato local, tendo, em decorrência disso, autonomia necessária para aplicar suas atividades tecnológicas no desenvolvimento de produtos. A inovação para este segmento de mercado é fator crucial no processo competitivo, no entanto, produtos ambientalmente corretos estão sendo mais atrativos às empresas inovadoras, pois além de proporcionarem diferencial competitivo, apresentam uma trajetória inovadora que facilita seus investimentos em recursos, por exemplo, por meio da busca por alternativas tecnológicas na biodiversidade. $\mathrm{O}$ quadro a seguir mostra a trajetória tecnológica.
6. Análise dos Resultados sobre o Desenvolvimento das Capacidades para a Inovação

Os modelos Stage-Gate (COOPER, 1990) e (DODGSON, 2008), são apresentados como ferramenta base pelas quais este estudo foi fundamentado. A partir destes modelos, constituíram-se alguns eixos de investigação, os quais formam as categorias de análise, como segue:

a) capacidades de inovação no nível de gestão da inovação tecnológica;

b) capacidades de inovação no nível tecnológico;

c) capacidades de inovação na área de P\&D;

d) capacidades de inovação no nível de desenvolvimento de produtos e processos;

e) capacidades de inovação no nível de sustentabilidade;

f) capacidades de e inovação em subsidiárias de corporações multinacionais; 
Por meio da interpretação destas categorias de análise, foi possível identificar e qualificar o desenvolvimento das capacidades para a inovação do objeto de pesquisa estudado, uma vez que foram comparadas as respostas obtidas nas entrevistas com a teoria consultada.

\subsection{Capacidades de Inovação no nível da}

\section{Gestão da Inovação Tecnológica}

Existe um aproveitamento parcial aos modelos apresentados por Cooper (1990:1996) e Dodgson (2008), que diferem entre si de acordo com cada unidade de negócios envolvida.

Figura 3: Ferramenta de Inovação Cognis - SBU Cosméticos
$\mathrm{Na}$ unidade de Nutrição \& Saúde, não existe desenvolvimento de produtos, uma vez que o modelo de negócios adotado na região é realizado por meio de revenda de produtos importados da matriz na Alemanha e da subsidiária americana. Porém, para a unidade agroquímica, pertinente à unidade estratégica de negócios intitulada Produtos Funcionais, o processo de desenvolvimento da inovação para novos produtos ou aplicação é gerenciado segundo o modelo de diretrizes da matriz, conforme o modelo abaixo:

\section{Conhecimento de Mercado}

Checagem da Sinergia Tecnológica
Fase de inovação

Checagem Progresso do Projeto

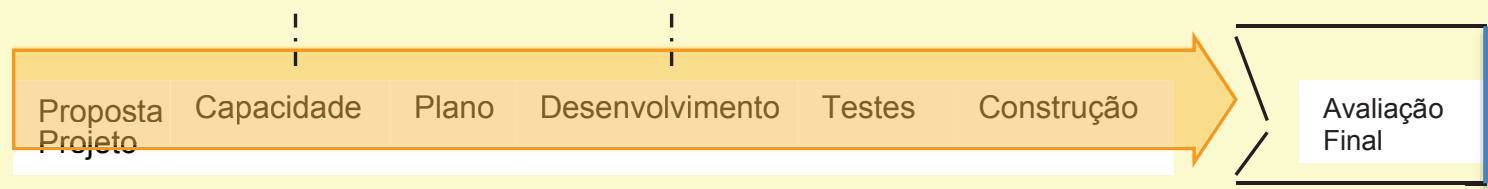

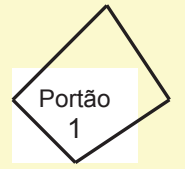
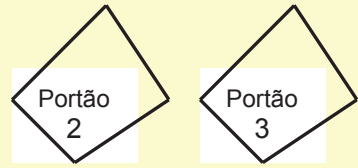

$$
\begin{aligned}
& \text { Aceitação } \\
& \text { em } \\
& \text { Progresso }
\end{aligned}
$$
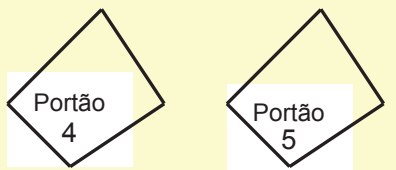

Aceitação

pelo

cliente

(pedido

firme)
Fase de Desenvolvimento

Fonte: Elaborado e adaptado pelo autor. 
Figura 4 - Estratégia Global de Negócios da Cognis _ SBU Agroquímica

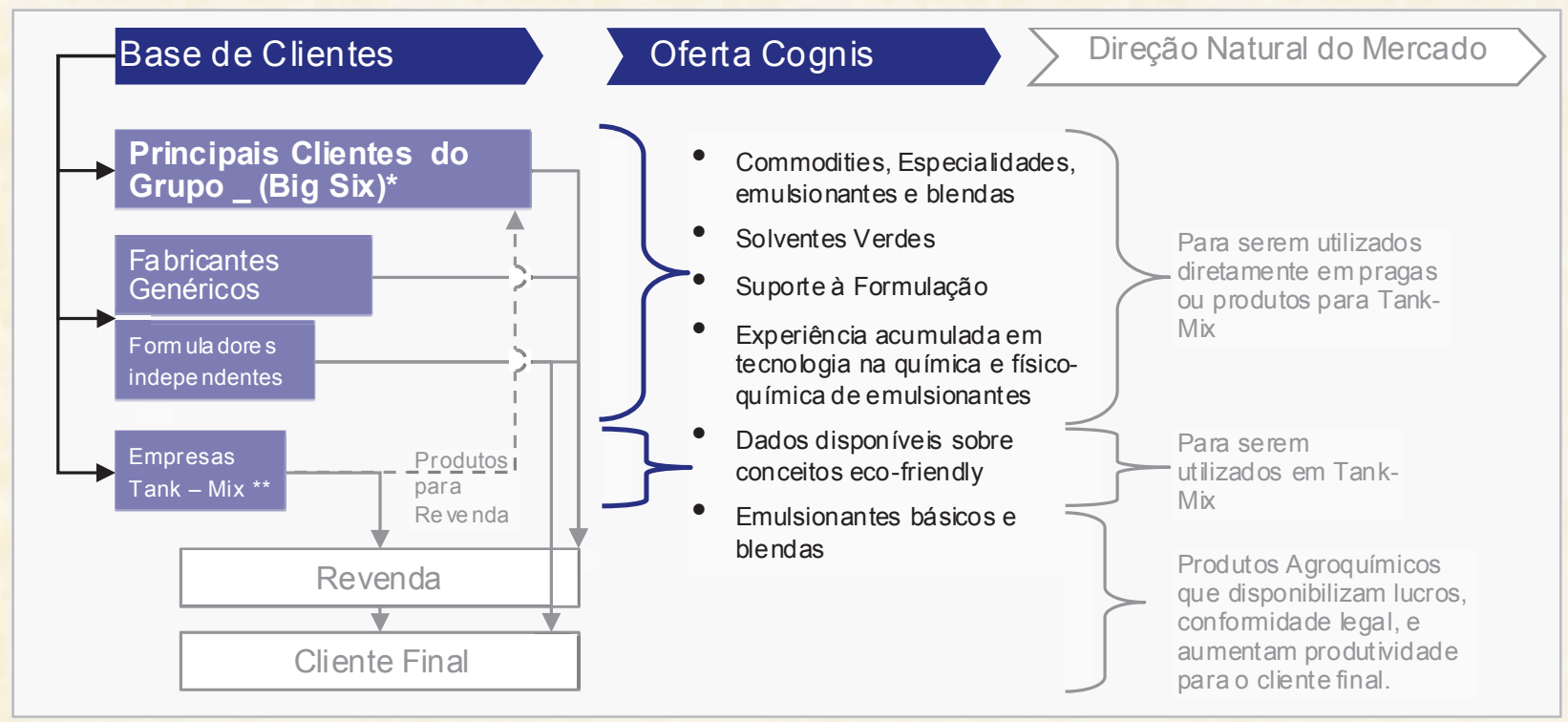

* Big Six: são os 06 maiores clientes da Cognis no mundo.

** Tank-Mix: são produtos misturados diretamente no campo antes da aplicação.

Fonte: Cognis, (2010).

\subsection{Capacidades de Inovação no Nível}

\section{Tecnológico}

A intensidade de conhecimento tecnológico baseia-se no número de projetos alcançados por meio de esforços relacionados à pesquisa e decorre do perfil de suas estratégias e que são aqui analisadas à luz da taxonomia de Freeman (1975). Caracteriza-se pela adoção de estratégia tecnológica ofensiva, procurando alcançar liderança técnica e de mercado em relação aos seus concorrentes. Para atender as metas da empresa, os pesquisadores dessa área trabalham utilizando, em média,
$70 \%$ de seu tempo. Utilizam o restante do tempo para o desenvolvimento de ideias próprias das suas respectivas regiões. Cada região possui um grupo de pesquisadores que conta também com a figura dos líderes de plataforma de tecnologia que são subdivididas em (sub) tecnologias. Cada uma tem um líder cujo papel é o de coordenar todas as atividades relacionadas a essas tecnologias. Ex.: Aditivos para tintas, águas, agrícolas, etc. Dessa forma, cada região além de trabalhar em projetos regionais, trabalha também em alguns dos projetos do pipeline global. Um projeto que faça parte do pipeline global pode ser empreendido por uma única subsidiária, mas pode também ser empreendido por mais de uma subsidiária que, desse modo, desenvolve conjuntamente o projeto. Cada projeto pode estar associado a um ou a vários clientes. 


\section{DIVERSQ!}

Os centros de pesquisa em aplicação são descentralizados da matriz e classificados em plataformas químicas, pois têm autonomia para desenvolverem ou adaptarem produtos de acordo com a regionalização. Estes centros de pesquisa aplicada possuem líderes de tecnologia que administram o processo de inovação de acordo com a estratégia da matriz. Todos os centros de pesquisa discutem suas se inicia em uma subsidiária e pode ser aproveitado em outros mercados do mundo, inclusive pela própria matriz, que ao mesmo tempo pode ser geradora do projeto, e/ou apenas receptora e difusora da solução apresentada.

\subsection{Inovação na Área de P\&D}

Figura 5: Critério para Estruturação e Desenvolvimento do Pipeline de Projetos

necessidades,

elaborando

um

pipeline de projetos de acordo com a captura das necessidades do mercado/clientes locais. Cada projeto, é elaborado segundo perspectivas do mercado regional e

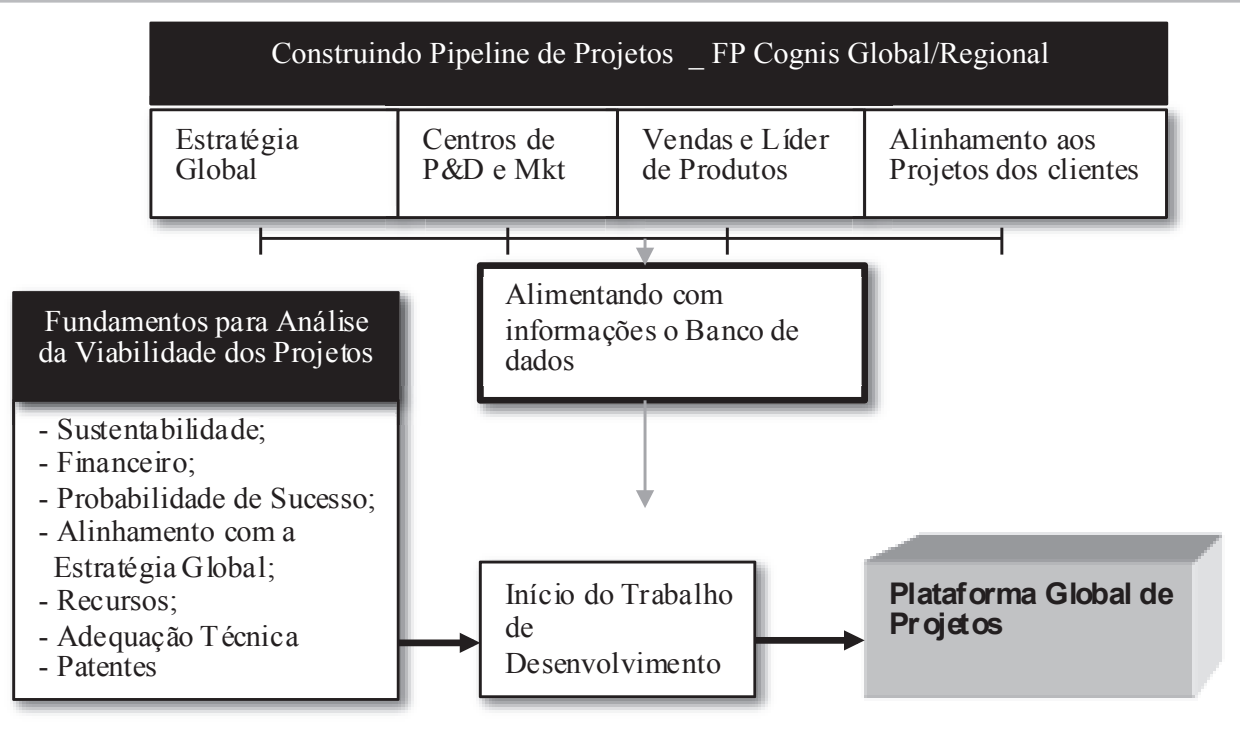
adota critérios como: sustentabilidade, probabilidade de sucesso, montante do valor de investimento, rentabilidade e tempo de retorno do investimento, e alinhamento com a plataforma química global. Um comitê internacional de tecnologia sediado na matriz, faz apreciação sobre a viabilidade técnica e econômica do projeto, o qual, se aprovado, entra em portfólio de desenvolvimento global sendo difundido à todas as regiões por meio de um banco de dados de projetos. Com isto, é estruturado um pipeline baseado na estratégia global que
Fonte: Elaborado pelo Autor. Cognis, 2009.

\subsection{Capacidades de Inovação na área de P\&D}

Como conceito, a estrutura de P\&D da Cognis é matricial e global. Os gastos em P\&D global indicam que 0 investimento e graus de intensidade da área de $P \& D$ na região ficam em torno da média global de $2,50 \%$ do faturamento líquido da matriz na Alemanha. 


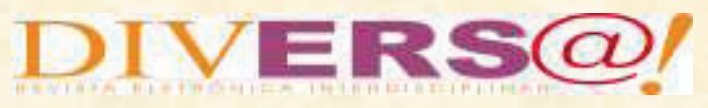

Tabela 4: Gastos Globais em P\&D em todas as SBU

definidas de análise crítica de projetos, estágios do processo de desenvolvimento,

\begin{tabular}{l|c|c|}
\hline & 2007 & 2008 \\
\hline Gastos com P\&D (*) & 81 & 85 \\
\hline $\begin{array}{l}\text { Menos: amortização } \\
\text { inclusive despesas com }\end{array}$ & $(33)$ & $(34)$ \\
P\&D & & 10 \\
\hline $\begin{array}{l}\text { Adição: capitalização com } \\
\text { custos de desenvolvimento }\end{array}$ & 8 & $\mathbf{6 1}$ \\
\hline Total de despesas com & $\mathbf{5 6}$ & 25 \\
P\&D & 26 & $\mathbf{8 6}$ \\
\hline Adição: custos extras de & $\mathbf{8 2}$ & \\
P\&D & & \\
\hline Total & & \\
\hline (*) gastos em milhões de euros, representando aproximadamente 3,49\% em relação ao \\
faturamento líquido.
\end{tabular}

bem como da distribuição das responsabilidades de cada funcionário envolvido no processo de desenvolvimento.

Os novos desenvolvimentos podem surgir por meio de diversas fontes. É aberto quando evidenciado que o produto ou

Fonte: Relatório anual Cognis, 2007/2008.

Além de desenvolver novos produtos processo tem potencial de comercialização. Depois de levantada a necessidade de um e ser uma grande geradora de novas tecnologias, a área de tecnologia e inovação das subsidiárias é responsável por adaptar seus produtos para as condições de regionalização das soluções criadas em outras filiais ou regiões do mundo, sempre respeitando a estratégia da matriz e a filosofia global de trabalhar com matériasprimas de origem natural e fontes renováveis sem agredir o meio ambiente.

\subsection{Capacidades de Inovação no nível de} Desenvolvimento de Produtos e Processos

O desenvolvimento de produtos, conforme procedimento ISO 9000 e ISSO 14000 da organização inclui etapas bem novo desenvolvimento, o trabalho pode ser iniciado por meio de duas atividades distintas: pesquisa exploratória ou a abertura imediata de projeto. A abertura do projeto é realizada quando no seu início já existam informações suficientes para o preenchimento do plano do projeto e desenvolvimento, ou após os resultados da pesquisa exploratória. A pesquisa exploratória é utilizada para identificar o potencial técnico e comercial de um novo produto ou de uma nova aplicação para um produto já existente, compreendendo exclusivamente a escala laboratorial, incluindo os processos específicos. Este processo pode resultar em diferentes tipos de projetos, tais como: nova embalagem de 
produto já existente, novo nome comercial, reativação de produto cancelado, produtos de revenda ou no desenvolvimento de novo produto ou novo processo. Esta etapa é caracterizada por análise crítica de projeto em que são avaliados os critérios de ganho de mercado, desempenho, viabilidade técnica, rentabilidade e ciclo de vida do produto. Estas atividades de busca de mercado são realizadas pelas áreas de vendas, marketing ou desenvolvimento, por meio da solicitação explícita dos clientes ou pelo resultado das atividades de pesquisa. A abertura do projeto é realizada quando no seu início já existam informações suficientes para o preenchimento do plano do projeto e desenvolvimento, ou após os resultados da pesquisa exploratória.

\subsection{Capacidades de Inovação no nível de}

\section{Sustentabilidade}

Embora existam trabalhos científicos que procuram descrever a eficiência e eficácia dos indicadores de sustentabilidade (VEIGA, 2010), o questionamento sobre métricas que possam medir o real do impacto do uso dos recursos naturais e a resiliência do planeta, continuam em discussão. Embora o tema sustentabilidade (ambiental) seja um tema ainda "oneroso" aos empresários, pode ser conciliável à sustentabilidade (financeira) das organizações, podendo ser considerado fator de vantagem competitiva e de criação de valor aos acionistas (HART e MILSTEIN, 2004), pelo aproveitamento das oportunidades de alteração do modelo de negócios a partir da elaboração de produtos a partir de fontes renováveis e produtos focados na base da pirâmide (PHARALAD, 2005). Desta forma, a estratégia da Cognis esta centrada na utilização de matérias-primas provenientes de fontes naturais, conforme será descrito no quadro abaixo, protegendo o meio ambiente. A empresa também se preocupa com o bem estar social, promovendo vários programas sociais ao redor do mundo. Isto faz com que seus colaboradores sejam qualificados e orientados tanto para seu sucesso profissional quanto para o sucesso da companhia.

O entendimento de sustentabilidade da companhia abrange quatro áreas ligadas entre si: (i) Meio Ambiente: baseado em desenvolvimento de produtos provenientes de fontes renováveis, (ii) Pessoas: desenvolvimento de programas sociais à comunidade, (iii) Produtos: por meio das capacidades inovadoras em relação às tecnologias de biomassa e soluções inteligentes, permite o crescimento de mercado com viabilidade de sucesso sustentável, (iv) Companhia: toda a empresa aplica padrões de segurança, saúde, meio ambiente e qualidade, ou seja, pratica o programa SHEQ de qualidade, além de outras certificações como, ISO9000 e 14000, Selo Abrinq e Abiquim, 


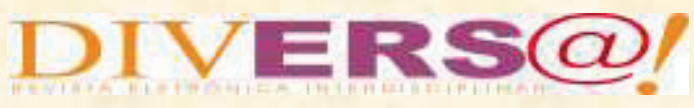

de manuseio de química responsável e amiga da criança.

Quadro 2: Conceito de Sustentabilidade na Cognis Brasil

BOX 1 Uma nova Fonte de Insumos nara a Connic Rracil

A diversidade de plantas (biodiversidade) e o tamanho da agricultura brasileira fazem que o país seja uma localização relevante para as unidades de negócios da Cognis. A estratégia da empresa objetiva reduzir sua dependência de commodities, e a tendência na Cognis Brasil é a de especializar-se em produtos de baixo volume e alto valor agregado. A ideia é transformar derivados de matérias-primas, tais como óleo de coco e óleos da Amazônia, em matérias especiais de maior valor agregado [...].

A Cognis possui uma certificação oficial do Instituto Brasileiro do Meio Ambiente e dos Recursos Naturais Renováveis (IBAMA) e de órgãos internacionais referente à exploração sustentável dos óleos da Amazônia. Foi pela competência demonstrada e pelo acesso à biodiversidade que a Cognis Brasil conquistou a responsabilidade para o desenvolvimento de componentes para a linha étnica da multinacional.

Como o adensamento das atividades tecnológicas da subsidiária na região por meio de projetos e desenvolvimentos específicos, caracteriza então, a autonomia da empresa local, portanto, a subsidiária brasileira tornou-se cada vez mais um centro importante de competências pelo alto nível de descobertas sobre novas misturas e aplicações destas moléculas, sucedendo as atividades tecnológicas em grau de importância da subsidiária americana. A partir da descentralização, foi possível estabelecer vantagem competitiva pelo atendimento rápido e pelo entendimento das exigências dos mercados locais, como: adaptação de recursos, logística, gestão de produtos e processos, aumentando o ciclo de vida dos produtos (Schumpeter,1961), permitindo visão global destes produtos. Esta descentralização das atividades técnicas conferem intensidade das atividades tecnológicas ajudando a empresa a ganhar mercados internos e exportar tecnologias. Também implica em concorrência entre as subsidiárias e adaptação de uso regional de cada produto justificado pelo fato de que cada mercado possuir características específicas, Gomes (2003).

\section{Considerações finais}

$\mathrm{O}$ estudo permitiu observar junto à empresa que as rotinas de trabalho relacionadas ao desenvolvimento das capacidades para a inovação não são feitas de forma sistemática, tampouco utilizam-se das mesmas ferramentas entre as SBU, contudo, é uma atividade interna consistente que está em dinâmico aperfeiçoamento, principalmente nas rotinas baseadas na troca de informações tecnológicas com a matriz. De acordo com o modelo analítico de ferramentas e técnicas de suporte às capacidades dinâmicas desenvolvido por Dodgson (2008), utilizado nesta pesquisa, permitiu contribuir para o entendimento da trajetória de desenvolvimento das capacidades locais para a inovação da Cognis Brasil. A partir 
de uma perspectiva teórica, este trabalho, via análise de modelo, procurou contribuir com seis categorias de análise: capacidades de inovação no nível de gestão da inovação tecnológica; capacidades de inovação no nível tecnológico; capacidades de inovação na área de P\&D; capacidades de inovação no nível de desenvolvimento de produtos e processos; capacidades de inovação no nível de sustentabilidade e por fim, da capacidades de inovação em subsidiárias de corporações multinacionais. A Cognis Brasil, desenvolve sua trajetória de capacidades para a inovação mesclando a utilização de ferramentas e modelos de desenvolvimento de projetos consolidados na literatura como o funil da inovação (COOPER, 1990:1996) e o modelo de suporte às capacidades dinâmicas (DODGSON, 2008), com suas próprias estruturas de pipelines globais baseadas em suas estratégias.

Este estudo de caso interage uma complexa teoria sobre a trajetória de desenvolvimento tecnológicas de organizações multinacionais, pois identifica que o desenvolvimento das capacidades para a inovação é demonstrado por meio dos projetos de acordo com a plataforma de necessidades de cada SBU e da realidade dos mercados que fazem parte da rotina da empresa, não sendo necessariamente estruturado em todas as fases do processo de inovação conforme identificado nos modelos citados como se fosse um projeto único. Este critério no desenvolvimento de capacidade para a inovação pode ser analisado a partir de duas perspectivas: (i) se por um lado a empresa deixa claro que a preocupação com a inovação faz parte das rotinas da companhia e perfazem o dia-a-dia de trabalho, e que, independentemente das ferramentas de controle, as inovações são implementadas e atendem a necessidade do cliente; (ii) por outro lado, a pesquisa também indica que um controle mais detalhado do processo inovativo, se tratado cada qual como um projeto com acompanhamento das fases conforme o modelo de gestão apresentados por Dodgson (2008) e do modelo que consta dos estudos de Cooper (1990:1996), poderia facilitar a viabilidade da inovação e aperfeiçoar o processo de gerenciamento das capacidades inovativas. A adoção de um modelo próprio de gestão das capacidades inovativas mostrou-se positivo e notório na avaliação deste estudo sob vários critérios, como por exemplo, do reconhecimento dos clientes em parcerias conjuntas e do aumento da rentabilidade dos novos produtos lançados.

Uma das limitações deste estudo incorre no fato de ter sido realizado estudo de caso único, embora revele grandes contribuições a respeito da trajetória de desenvolvimento das capacidades locais para a inovação em subsidiárias brasileiras. Embora a Cognis Brasil seja pioneira neste modelo de desenvolvimento tecnológico, ampliar os estudos de múltiplos casos poderiam contribuir de forma mais sólida ao campo de estudo. Além disto, a quantidade de entrevistados, mesmo que totalmente envolvidos no processo decisório da corporação, foi reduzido de 


\section{DIVERS@!}

acordo com os recursos disponíveis, sugerindo que um maior numero de entrevistados poderiam ser entrevistados em futuras pesquisas, avaliando-se os mesmos modelos e abrangência citados neste trabalho, ou ainda, utilizar modelos estatísticos de análise fatorial ou de regressão múltipla para medir a influências destas variáveis no processo de desenvolvimento tecnológico de subsidiárias locais de corporações multinacionais

Mesmo em relação a estas limitações, acreditamos que este trabalho tenha contribuído de forma empírica e significativa ao estudos do conhecimento dos estudos sociais neste campo de estudo.

\section{Referências}

BARBEY, B. J. Firm Resources and Sustained Competitive Advantage. Journal of Management, USA, v.17, n 1, p.99-120, 1991.

COOPER, R. G. Stage -gate systems: a new tool for managing new products, Business Horizons, p.45-55, may-june, 1990.

KLEINSCHIMDT, E. J. Winning business in product development: the critical success factors. Research Technology Management, v.39, n.4, p.1830, July-august 1996.

DODGSON, M.; GANN, D.; SALTER, A. The Management of Technological Innovation. New York, Oxford University Press, 2008.

FLEURY, M.T.L.; FLEURY, A. Construindo o conceito de competência. Revista de Administração Contemporânea, ed. esp. P. 183-196, 2001.
FREEMAN, C., Innovation and the strategy of the firm, in: _ The economics of industrial innovation. Harmondsworth: Penguin Books; 1975. p. 225- 282.

GOMES, R.; O Papel das Subsidiárias e a Internacionalização das Atividades Tecnológicas pelas Empresas Transacionais (ETNs), GESTÃO \& PRODUÇÃO, v.10, n.3, p.267-281, dez. 2003.

HART, S. L.; MILSTEIN, M. B. Criando Valor Sustentável. RAE - Revista de Administração de Empresas, vol. 3, n.2, p.65-79, mai./jun., 2004.

MARTINELLI, O. Relatório Setorial Final do Setor de Agroquímicos. São Paulo: FINEP, 2005.

MINTZBERG, H., Five Ps for Strategy, em: The Strategy Process, revised European Ed., Prentice-Hall, New Jersey, 1998.

OLIVEIRA JUNIOR, M. M.; BOEHE, D. M.; BORINI, F. M. Estratégia e Inovação em Corporações Multinacionais: A transformação das subsidiárias brasileiras. 1 ed. São Paulo: Saraiva, 2009.

PRAHALAD, C. K. A Riqueza na Base da Pirâmide: Como Erradicar a Pobreza com o Lucro. Porto Alegre: Bookman, 2005.

PORTER, M. E. Estratégia Competitiva. Técnicas para Análise de Indústrias e Competidores. $23^{\mathrm{a}}$ ed. Rio de Janeiro: Campus, 1980.

QUADROS, R. Padrões de Desenvolvimento da inovação Tecnológica em Empresas Brasileiras: as diferenças por tamanho, nacionalidade e setor de negócios. Relatório de Pesquisa para o CNPq, DPCT/UNICAMP, Campinas, 2005.

QUADROS, R. et al. Desenvolvimento da inovação Tecnológica: Uma Análise da Aplicação do Funil de Inovação em uma Organização de Bens de Consumo, RAM Revista de Administração Mackenzie, Volume 8, n.1, 2007, p. 77-107. 
SCHUMPETER, J. A . Teoria do desenvolvimento econômico: uma pesquisa sobre lucros, capital, crédito, juros e ciclo econômico. Rio de Janeiro: Fundo de Cultura, 1961.

TEECE, J. D; PISANO, G.; SHUEN, A. Dinamic Capabilities and Strategic Management. Strategic Management Joumal, USA, Vol. 18:7, 509-533 (1997).

TIDD, J; BESSANT, J.; PAVITT, K. Desenvolvimento da inovação. $3 \mathrm{ed}$. Porto Alegre: Bookman, 2008.

VEIGA, José Eli da. Indicadores de sustentabilidade. Estudos Avançados, v. 24 , n. 68,2010 , p. $39-52$.

VILHA, A. M.; QUADROS, R. Estratégias e práticas de gestão de inovação sob a perspectiva do desenvolvimento sustentável: estudo exploratório em empresas do setor de higiene pessoal, perfumaria e cosméticos. ENANPAD, Rio de Janeiro, 2008.

WERNERFELT, B. A resource-based view of the firm. Strategic Management Journal, vol. 5, p.171-180, 1984.

\footnotetext{
${ }^{\text {i }}$ Pipeline, significa projetos em desenvolvimento.

${ }^{2}$ Em 2009 foram depositadas 17 patentes regionais

3 A Cognis identifica e entende como novos produtos, os produtos lançados nos últimos cinco anos, sejam eles por introdução de um novo produto no mercado regional por revenda do produto da matriz, mudança significativa das especificações de um produto já conhecido, ou descobrimento de um novo mercado através de um produto já desenvolvido e que faz parte do portfólio de produtos regulares.
} 